\title{
Locus of pain control associated with medication adherence behaviors among patients after an orthopedic procedure
}

This article was published in the following Dove Press journal:

Patient Preference and Adherence

16 July 2014

Number of times this article has been viewed

\author{
Thaisy Mendes Porto' \\ Daniele Caferatti Machado' \\ Rafael Olívio Martins ${ }^{2}$ \\ Dayani Galato 3 \\ Anna Paula Piovezan ${ }^{3}$ \\ 'Course of Pharmacy, ${ }^{2}$ Course of \\ Medicine, ${ }^{3}$ Post-Graduation in Health \\ Sciences, University of Southern Santa \\ Catarina, Tubarão, Santa Catarina, \\ Brazil
}

Background: Locus of pain control (LPC) is characterized by the behavior of people coping with their health problems, as a result of their own actions (internal control) or external factors or other people (external control). This parameter can be associated with medication adherence, in addition to other psychosocial factors that may also influence this behavior. This study was performed to investigate the influence of the LPC on medication adherence in patients undergoing an orthopedic procedure.

Subjects and methods: We conducted a prospective cohort study on patients who attended an orthopedic clinic for arthroscopy treatment. The patients' LPC and pain intensity data were obtained on the day of admission through the use of the LPC scale and the visual analog scale (VAS), respectively, both being validated tools. After arthroscopic surgery, the patients received drug prescriptions and were reassessed after 15 days regarding treatment adherence, using the Morisky test. A $P$-value $<0.05$ was considered statistically significant.

Results: We assessed 79 individuals from both the internal LPC group $(n=35)$ and external LPC group $(n=44)$ and found that there were no group differences in sex, affected limb, cause of injury, repetitive strain injury, duration of pain, or pain intensity. However, there was a higher proportion of patients in the external LPC group that adhered to the prescribed medication compared with the internal LPC group $(P<0.01)$.

Conclusion: The results showed that among patients who underwent an orthopedic procedure, there was a higher adherence rate to prescribed medication in the external LPC group compared with the internal LPC group.

Keywords: behavior, locus of control, compliance

\section{Introduction}

Treatment adherence is a complex behavior that deserves further study, because it is influenced by several factors, ${ }^{1}$ either related to the patient and treatment method, or the health care service. Among the patient-related factors, sociodemographic characteristics are associated with medication adherence, ${ }^{2}$ but psychological and emotional factors have also been investigated, ${ }^{3}$ because the way that patients cope with their health problems and treatment may have a direct influence on medication adherence. ${ }^{4-6}$ This may be true, especially when the treatment is performed for pain management. One way to assess this form of coping with pain is by assessing the locus of pain control (LPC).

The Multidimensional Health Locus of Control Scale was initially developed to evaluate this parameter. Individuals are characterized with regard to the perception of their general health-related status, either due to their own actions (internal control), 
or external factors and other people (external control). ${ }^{7}$ The adapted Pain Locus of Control-C scale was formulated to explain the perception of individuals regarding who or what has specific control of their pain. In Brazil, this instrument was validated ${ }^{8}$ and adapted ${ }^{9}$ for use in elderly patients with nonmalignant chronic pain.

In this context, understanding the influence of LPC on medication adherence may allow the understanding of this phenomenon in patients with other health conditions. Thus, the aim of the current study was to evaluate the influence of the LPC on medication adherence in patients undergoing orthopedic surgery, given that treatment of patients with musculoskeletal disorders is affected by discontinuation of prescribed drugs ${ }^{10}$ and seems to be significantly influenced by people's perceptions. ${ }^{11}$

\section{Methods}

This prospective cohort study was conducted on patients who attended an orthopedic clinic for arthroscopy in Tubarão, Santa Catarina, Brazil.

The study subjects were patients undergoing an arthroscopic procedure of the shoulder or knee, from March-May 2012. Participants had to be 18 years or older, be able to respond to the assessment tools, agree to participate, and sign the consent form. The patients who were not available for the last data collection were excluded from the study.

After arthroscopic surgery, the patients received a standard prescription of drugs that contained the following: a) cephalexin $500 \mathrm{mg}$ orally every 6 hours, for its antibiotic activity; b) orally dispersible nimesulide $100 \mathrm{mg}$ every 12 hours, for its anti-inflammatory activity. The arthroscopic surgery was performed by a single orthopedic surgeon, who was also responsible for the reassessment of patients 15 days after the procedure regarding their improvement in functional status and adherence to the prescribed medications.

Sample size determination required a minimum of 35 subjects per group, considering the following parameters: a $50 \%$ proportion of adherent individuals, a relative risk of 1.7 , and $90 \%$ power at a $5 \%$ significance level for twotailed tests.

The patients who fulfilled the inclusion criteria were consecutively selected until the minimum number of individuals per group (internal and external LPC) was reached. Data collection occurred in two stages, of which the first was performed during the patient's hospitalization before the arthroscopic surgery. After explaining the research purpose, informed consent was obtained and the LPC scale was administered..$^{9}$ The adapted LPC scale is administered in an interview format. It has 14 items divided into four subscales, which correspond to the factors evaluated by the instrument, and can be used separately. The four response options range from "I strongly disagree" (1 point) to "I strongly agree" (4 points). Each subscale receives independent scores, with the one that receives the highest score being predominant. ${ }^{9}$ In addition, the following sociodemographic and clinical characteristics were collected: sex, age, affected limb, cause of injury, and duration of pain. The patients returned for reassessment 15 days after arthroscopy. At this second stage, the visual analog scale (VAS) ${ }^{12}$ was used to measure pain intensity over this period. In addition, the Morisky scale was used to measure medication adherence. This test is applied in a questionnaire format, and consists of a structured four-item measure of self-reported medication adherence. It has the advantage of being easy to use, and despite having been validated for hypertensive patients, ${ }^{13}$ according to the literature, it is widely used for other conditions. Descriptive analysis was performed on the sociodemographic variables, internal and external LPC, and pain intensity (mild-tomoderate: $0-5$ points; intense: $5.1-10$ points). With regard to medication adherence as a dependent variable, the patients were categorized as adherent or nonadherent. The chi-square or Fisher's exact test and Student's $t$-tests were used for comparison between groups. A $P$-value $<0.05$ was considered statistically significant.

The study protocol was approved by the Research Ethics Committee of the University of Southern Santa Catarina (number 11.542.4.03.III), in compliance with Resolution 196/96 of the Brazilian National Health Council, which is in accordance with the Helsinki Declaration.

\section{Results}

A total sample of 79 patients was surveyed. The mean age was $44.0 \pm 14.7$ years, ranging 20-77 years. The patients in the internal LPC group showed a lower mean age (41.8 \pm 13.1 years) compared to those in the external LPC group (46.6 \pm 16.1 years), which revealed no statistically significant differences related to this variable. Additional characteristics of these patients are shown in Table 1.

With regard to the sex-related affected limb (shoulder or knee), a higher proportion of women (82.1\%) had shoulder surgery, whereas a higher proportion of men $(90 \%)$ had knee surgery. With regard to the main cause of injury, it was observed that shoulder injury was most commonly due to work in women (63.7\%), whereas knee lesions were predominantly linked to leisure in men $(40.7 \%)$. 
Table I Demographic profile and clinical characteristics of the surveyed patients, distributed according to the expressed LPC ( $\mathrm{n}=79$ )

\begin{tabular}{|c|c|c|c|c|c|}
\hline Variable & Total n (\%) & Internal LPC n (\%) & External LPC n (\%) & $P$-value ${ }^{a}$ & $P$-value ${ }^{b}$ \\
\hline Sex & & & & 0.349 & 0.966 \\
\hline Men & $52(65.8)$ & $25(7 \mid .4)$ & $27(6 \mathrm{I} .4)$ & & \\
\hline Women & $27(34.2)$ & $10(28.6)$ & $17(38.6)$ & & \\
\hline Affected limb & & & & $0.74 I$ & 0.393 \\
\hline Shoulder & $30(37.9)$ & $14(40.0)$ & $16(36.4)$ & & \\
\hline Knee & $49(62.1)$ & $21(60.0)$ & $28(63.6)$ & & \\
\hline Cause of injury & & & & 0.361 & 0.533 \\
\hline Leisure & $36(45.6)$ & I8 (5।.4) & $18(40.9)$ & & \\
\hline Work & $17(2 \mid .5)$ & $05(14.3)$ & $12(27.3)$ & & \\
\hline Others & $26(32.9)$ & $12(34.3)$ & $14(31.8)$ & & \\
\hline Repetitive strain injuryc & & & & 0.741 & 0.013 \\
\hline Yes & $49(62.0)$ & $21(60.0)$ & $28(63.6)$ & & \\
\hline No & $30(38.0)$ & $14(40.0)$ & $16(36.4)$ & & \\
\hline Duration of pain & & & & 0.302 & 1.000 \\
\hline$<$ I year & $46(58.2)$ & $19(54.3)$ & $27(6 \mathrm{I} .4)$ & & \\
\hline$\geq \mathrm{I}$ year & $33(41.8)$ & $16(45.7)$ & $17(38.6)$ & & \\
\hline Pain intensity ${ }^{d}$ & & & & 0.090 & 0.905 \\
\hline Mild or moderate & $51(64.6)$ & $26(74.3)$ & $25(56.8)$ & & \\
\hline Intense & $28(35.4)$ & $09(25.7)$ & $19(43.2)$ & & \\
\hline
\end{tabular}

Notes: ${ }^{a}$ Chi-square test; badjusted by logistic regression; caggravating factor; ${ }^{d}$ before arthroscopic procedure.

Abbreviation: LPC, locus of pain control.

Adopting the recommended scoring method, the Morisky medication adherence scores revealed that out of the 79 surveyed patients, 46 (58.2\%) were adherent to the prescribed medications. Furthermore, no association was found between adherence behaviors and other variables analyzed in the current study.

With regard to the main research question of the current study, comparisons between groups showed that patients with external LPC had better adherence to prescribed medication than those with internal LPC $(P \leq 0.001)$, as illustrated in Figure 1 .

\section{Discussion}

To our knowledge, this is one of the first studies using the LPC scale that was recently adapted in Brazil ${ }^{9}$ to show an

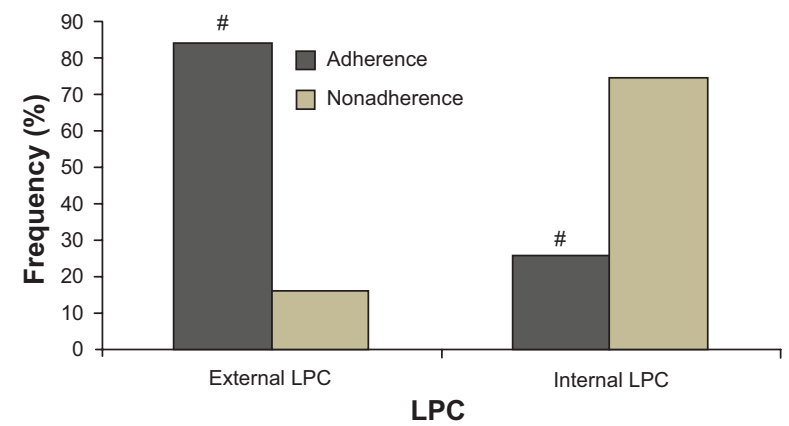

Figure I Association between medication adherence and LPC in patients undergoing arthroscopy.

Notes: Tubarão, State of Santa Catarina, $2012(n=79) ;{ }^{*} P<0.001$ in relation to nonadherence group.

Abbreviation: LPC, locus of pain control. association between this scale and medication adherence in patients undergoing orthopedic surgery. In the current study, the proportion of subjects who adhered to medication prescribed by the physician was significantly higher among patients who had external LPC.

Medication adherence is a complex behavior that is influenced by various factors, including those related to treatment, the health care team, and the patient. ${ }^{14}$ In the current study, neither the health care team nor the prescribed medications differed between the surveyed patients, which strengthened the idea that only factors related to the patients themselves changed. The lack of association between LPC and the other study variables revealed that the LPC-related factors were the most important aspects to be considered in the current study.

One can assume that the higher adherence rate to prescribed medication among the patients in this study is due to the belief that their cure is more dependent on external factors, such as the prescribed drugs, than their actions regarding their orthopedic health condition. This outcome supports the study that evaluated patients with chronic pain of nonmalignant origin during a 6-month period. ${ }^{15}$ In the mentioned study, internal LPC was associated with lower medication adherence compared with external LPC. The authors argued that people with external LPC tend to believe that factors that do not depend on themselves, such as fate, luck, or other people (health care providers, family members, and friends) have greater influence over their pain. Most of them believe 
that the presence of a health professional and rigorous adherence to medication are the most important factors affecting their pain management. In addition, the authors of that study claimed that the reason that patients with internal LPC have lower medication adherence than those with external LPC is likely because they believe that the improvement of their health status depends only on themselves. Therefore, they consider the situation and decide to discontinue drug therapy without the aid of a health professional.

Studies of this kind have contributed to the removal of these beliefs and improve health and well-being. If patients believe that there is little relationship between their individual actions and good health outcomes, they would probably seek the help of health services more often. ${ }^{8}$ The results presented here may contribute to positive actions by suggesting education programs directed towards promotion of health behaviors among patients with such characteristics, since nonadherence to medication in patients with pain, especially chronic pain, can result in disease progression and decreased quality of life. ${ }^{15}$

More importantly, health professionals should take coresponsibility in patient treatment. In that direction, a study that reviewed the available literature in Latin America on patients with chronic diseases emphasized that these professionals should consider the subjectivity of individuals, and their needs and difficulties, aiming at overcoming what seems to be a widespread view that the patient is the only one responsible for his or her treatment. ${ }^{1}$

On the other hand, the needs of the health professionals who deal with such patients should also be considered. A study that investigated nurses who attended patients with cancer pain pointed out that these professionals should be aware of the patent condition and treatment options, and be prepared and skilled at providing proper mental and emotional support. ${ }^{16}$ The latter aspect has a close relationship with the objectives of the current study. The findings presented here also help health professionals to understand that medication adherence behavior is multifactorial and complex, and is influenced by psychological factors as well.

The findings from this study strengthen the idea raised by the authors cited above ${ }^{16}$ on the need to train health professionals for effective, competent health care delivery. Actions directed at both the patients and their health care professionals, as recently proposed by a study on adolescents living with HIV/AIDS, ${ }^{17}$ would be the most effective ones.

Our findings showed great similarity between the internal and external LPC groups in the other variables assessed, which suggests that the recent publication of the LPC scale may contribute greatly to the understanding of psychological aspects related to the specific treatment of patients with pain. Previous studies on this issue were using the Health Locus of Control scale, ${ }^{18}$ which evaluates the individual's perception of more general health issues, rather than those only involving pain conditions. ${ }^{9}$ In the current study, the use of the LPC scale in patients with pain after orthopedic surgery has been shown to be an easy and useful tool for the comparison of medication adherence between individuals presenting differences in LPC, although it should be considered that the scale was adapted for the elderly, which can be seen as a limitation of the present study.

The findings from this study revealed that more than half of the surveyed subjects adhered to the treatment regimen. Other studies that used the Morisky scale as an assessment tool to address medication adherence in patients with different health conditions have found distinctive results, with adherence varying substantially. In this regard, it has been suggested that this fact could be dependent on the type of pathology ${ }^{19}$ or medication assessed, ${ }^{20}$ as well as the patients' beliefs about medication, among other factors. ${ }^{21}$

Our results are consistent with patients experiencing pain who underwent orthopedic surgery as defined in this survey. Further studies on other types of pain and procedures should be conducted to increase knowledge about the association between external LPC and medication adherence in patients with pain.

\section{Conclusion}

This study found a higher adherence rate to prescribed medication in patients that underwent orthopedic surgery with external LPC compared with internal LPC, which suggests that the health belief parameters help explain why individual patients may adopt or reject healthy behaviors. Further studies aimed at understanding the cognitive, social, and emotional aspects involved in medication adherence, and the role of health professionals in the delivery of health care, are of utmost importance. Health professionals can greatly contribute towards strategies to cope with nonadherence to medication.

\section{Disclosure}

The authors report no conflicts of interest in this work.

\section{References}

1. Reiners AA, Azevedo RC, Vieira MA, de Arruda AL. Produção bibliográfica sobre adesão/não-adesão de pessoas ao tratamento de saúde. [Bibliographic production about adherence/non-adherence to therapy]. Cien Saude Colet. 2008;13 Suppl 2:2299-2306. Portuguese. 
2. Gimenes HT, Zanetti ML, Haas VJ. Factors related to patient adherence to antidiabetic drug therapy. Rev Lat Am Enfermagem. 2009;17(1):46-51.

3. Dosse C, Cesarino CB, Martin JF, Castedo MC. Factors associated to patients' noncompliance with hypertension treatment. Rev Lat Am Enfermagem. 2009;17(2):201-206.

4. Gusmão JL, Mion Jr D. Adesão ao tratamento - conceitos. [Adherence to the treatment - concepts]. Rev Bras Hipertens. 2006;13(1):23-25. Portuguese.

5. Axelsson M, Cliffordson C, Lundbäck B, Lötvall J. The function of medication beliefs as mediators between personality traits and adherence behavior in people with asthma. Patient Prefer Adherence. 2013;7:1101-1109.

6. Molfenter TD, Bhattacharya A, Gustafson DH. The roles of past behavior and health beliefs in predicting medication adherence to a statin regimen. Patient Prefer Adherence. 2012;6:643-651.

7. Wallston KA, Wallston BS, deVellis R. Development of the Multidimensional Health Locus of Control (MHCL) scales. Health Educ Behav. 1978;6(2):160-170.

8. Araújo LG, Lima DM, Sampaio RF, Pereira LS. Escala de Locus de controle da dor: adaptação e confiabilidade para idosos. [Pain Locus of control scale: adaption and reliability for elderly.]. Rev Bras Fisioter. 2010;14(5):438-445. Portuguese.

9. Pereira LS, Araújo LG, Sampaio RF, Haddad JP. Factorial analysis of the Multidimensional Health Locus of control scale - Form C for elderly. Rev Bras Fisioter. 2011;15(5):363-370.

10. Gandhi R, Perruccio AV, Rampersaud YR. Predictors of willingness to undergo elective musculoskeletal surgery. Patient Prefer Adherence. 2013;7:191-197.

11. Rossini M, Bianchi G, Di Munno O, et al; Treatment of Osteoporosis in clinical Practice (TOP) Study Group. Determinants of adherence to osteoporosis treatment in clinical practice. Osteoporos Int. 2006;17(6):914-921.

12. Scott J, Huskisson EC. Graphic representation of pain. Pain. 1976;2(2):175-184.
13. Morisky DE, Green LW, Levine DM. Concurrent and predictive validity of a self-reported measure of medication adherence. Med Care. 1986;24(1):67-74.

14. World Health Organization. Adherence to Long-Term Therapies: Evidence for Action. Geneva, Switzerland: World Health Organization; 2003. Available from: http://www.who.int/chp/knowledge/publications/ adherence_full_report.pdf?ua=1. Accessed January 22, 2014.

15. Kurita GP, Pimenta CA. Adesão ao tratamento da dor crônica e o Locus de controle da saúde. [Compliance with the treatment of chronic pain and health control locus]. Rev Esc Enferm USP. 2004;38(3):254-261. Portuguese.

16. da Silva LM, Zago MM. O cuidado do paciente oncológico com dor crônica na ótica do enfermeiro. [Care for the oncologic patient with chronic pain from the point of view of the nurse]. Rev Lat Am Enfermagem. 2001;9(4):44-49. Portuguese.

17. Kourrouski MF, Lima RA. Treatment adherence: the experience of adolescents with HIV/AIDS. Rev Lat Am Enfermagem. 2009;17(6):947-952.

18. Oliveira TH, Oliveira VC, Melo RC, Melo RM, Freitas AE, Ferreira PH. Patients in treatment for chronic low back pain have higher externalised beliefs: a cross-sectional study. Rev Bras Fisioter. 2012;16(1):35-39.

19. Banerjee S, Varma RP. Factors affecting non-adherence among patients diagnosed with unipolar depression in a psychiatric department of a tertiary hospital in Kolkata, India. Depress Res Treat. 2013;2013:809542.

20. Muratore M, Quarta E, Quarta L. Intramuscular neridronate in patients with rheumatoid arthritis using corticosteroids: evaluation of treatment adherence in a randomized, open-label comparison with other bisphosphonates. Acta Biomed. 2013;84(1):23-9.

21. Rajpura J, Nayak R. Medication adherence in a sample of elderly suffering from hypertension: evaluating the influence of illness perceptions, treatment beliefs, and illness burden. J Manag Care Pharm. 2014;20(1):58-65.
Patient Preference and Adherence

\section{Publish your work in this journal}

Patient Preference and Adherence is an international, peer-reviewed, open access journal that focuses on the growing importance of patient preference and adherence throughout the therapeutic continuum. Patient satisfaction, acceptability, quality of life, compliance, persistence and their role in developing new therapeutic modalities and compounds to optimize

\section{Dovepress}

clinical outcomes for existing disease states are major areas of interest for the journal. This journal has been accepted for indexing on PubMed Central. The manuscript management system is completely online and includes a very quick and fair peer-review system, which is all easy to use. Visit http://www. dovepress.com/testimonials.php to read real quotes from published authors. 